\title{
Magnetically treated water on phytochemical compounds of Rosmarinus officinalis $\mathbf{L}$.
}

\author{
YilanFung Boix ${ }^{1}$, Elizabeth Isaac Alemán ${ }^{1}$, Jorge Molina Torres ${ }^{2}$, Enrique Ramírez \\ Chávez ${ }^{2}$, Rosanni do Carmo de Oliveira Arruda ${ }^{3}$, Sophie Hendrix ${ }^{4}$, Natalie Beenaerts ${ }^{4}$, \\ Cristiane Pimentel Victório ${ }^{5 *}$, Liliana Gómez Luna ${ }^{1}$, Clara Martinez Manrique ${ }^{1}$, Ann \\ Cuypers $^{4}$
}

\begin{abstract}
${ }^{1}$ National Center of Applied Electromagnetism (NCAE), Universidad de Oriente, Av Las Americas s/n, 5322 646378, Santiago de Cuba, Cuba.

${ }^{2}$ Laboratorio de Fitobioquimica. CINVESTAV, Unidad Irapuato. Km 9.6 Libramiento Norte, CP: 36821 Guanajuato. México.

${ }^{3}$ Laboratório de Anatomia Vegetal, Centro de Ciências Biológicas e da Saúde, Universidade Federal de Mato Grosso do Sul

(UFMS), Campo Grande, MS, Brazil

${ }^{4}$ Centre for Environmental Sciences, Hasselt University, Belgium

${ }^{5}$ Laboratório de Pesquisa em Biotecnologia Ambiental, Universidade Estadual da Zona Oeste (UEZO), Rio de Janeiro - RJ, 23070-200, RJ, Brazil.
\end{abstract}

\begin{abstract}
Irrigation using water treated with static magnetic field (SMF) has recently been used as a strategy to stimulate the growth and development of different plant species. The aim of this study was to characterize the bioactive compounds and evaluate the anatomical structure of Rosmarinus officinalis L. irrigated with SMF-treated water. Results demonstrate that the treatment promoted plant growth, the number of trichomes and increased concentrations of secondary metabolites. Methanolextracted leaves revealed that rosmarinic acid was detected in both experimental groups, without a difference in the level. Camphor, $\alpha$-terpineol and verbenone were determined as the most abundant compounds present in these leaf extracts and were strongly increased in plants irrigated with SMF-treated water. Similar results were also observed for endo-borneol, bornyl acetate and $\beta$-amyrin concentrations.Taken together, these results indicate that irrigation with SMF-treated water can be used to improve the production of rosemary to obtain pharmaceutical products with an increased antioxidative activity.
\end{abstract}

Keywords - rosemary, leaves, static magnetic field, thin layer chromatography, gas chromatography.

\section{INTRODUCTION}

Rosemary (Rosmarinus officinalis L.) is an aromatic plant of the Lamiaceae family that is frequently used in medicine. It is an important source of polyphenols and is known for its high antioxidative activity(Suong et al., 2011).The most abundant bioactive compounds in rosemary leaves are phenols, monoterpenes, diterpenes and their derivatives, including carnosic acid and related stable compounds such as carnosol, rosmanol, epirosmanol and 7methylepirosmanol(Al-Sereiti et al., 1999). Rosemary isoften used for the production of natural antioxidant extracts andis reported to have a strong therapeutic potential in the treatment and prevention of many diseases including asthma,spasmogenicdisorders, liver disordersand hepatotoxicity, peptic ulcers, inflammatory diseases, ischemic heart disease, arteriosclerosis, Alzheimer and poor sperm motility(Suong et al., 2011; Fernández L.F. et al., 2014).

Rosemary naturally grows throughout $\mathrm{Cuba}$ and is frequently found in home gardens. Recently, it has been removed from the Cuban National Formulations of Phytopharmaceuticals due toproblems associated with its cultivation. Indeed, rosemary has a poor vegetative propagation and low seed production. However, it is included inthe priority list of plants for the development of Natural and Traditional Medicine in Cuba(Report to the National Commission for the Development of Traditional and Natural Medicine, 2008), emphasizing the need to develop new rosemary cultivation strategies.

Irrigation with magnetically treated water is an interesting strategy to improve rosemary production, as magnetic fields are known to strongly affect shoot growth and seed germination. Indeed, many reports have described the use of magnetically treated water and magnetic fields in agriculture. Its use has been associated with an increased 
plant metabolism (photosynthesis and water uptake) and improved plant growth and production. Irrigation using water treated with a static magnetic field (SMF)has been used for the cultivation of several plant species including tomato (Solanum lycopersicum L.), cucumber (Cucumis sativum L.), rice (Oriza sativum L.), faba bean (Vicia faba L.), snow pea (Pisum sativum L var. macrocarpon) and chickpea (Cicer arietinum L.) (Gesterberger P. et al., 1978; Gilart F. et al., 2013; Grewal H.S. et al., 2011a).

This study aimed to characterize the bioactive compounds present in $R$. officinalis L. irrigated with SMF-treated water(100-150 mT)and to evaluate resulting changes in leaf histology underfield conditions.

\section{MATERIAL AND METHODS}

\section{Plant material}

Rosmarinus officinalis L. plants were cultivated onan experimental plot in Santiago (Cuba) and the leaves were used to preparemethanol extracts. Voucher specimen isdeposited at the Herbarium of Biodiversity and Ecology Center (BIOECO) under accession number RB 21324.

The experiment used an external magnetizer with permanent magnets designed, built and calibrated at the National Center of Applied Electromagnetism (NCAE).Magnetic induction ranged between 100 and 150 mT(Gilart F. et al., 2013). Plants were either irrigated with SMF-treated water(hereafter referred to as SMF plants) orwater not treated with SMF (referred to as control plants). Sixty plants were included in each treatment andgrown underthese conditionsfor 180 days. Irrigation was performed twice a day for 30 minutes through an air microjet system, consistingof aKSB ITUR pump and a valve-controlled system distributor. Irrigation was carried out using jets, which were set at aflow rate between 2.54 and $2.91 \mathrm{~m}^{3} \mathrm{~h}^{-1}$. Thewater velocityrangedbetween 1.4 and $1.6 \mathrm{~ms}^{-1}$.

\section{Scanning Electron Microscopy}

The analysis of trichome morphology and numberwas performed in leaf samples fixed in formalin-acetic acidalcohol (FAA) solution (70\%)(Johansen, 1940). For scanning electron microscopy (SEM), leaves were dehydrated in a graded ethanol series, submitted to critical point drying with $\mathrm{CO}_{2}$ (Leica EM CPD-030) and coated with a thin layer of gold (Denton Vacuum Desk IV, LLC). The samples were analyzed using a JEOL-JSM 6390 LV scanning electron microscope (Jeol USA Inc) as described byGesterberger P. et al. (1978).
Preparation of rosemary extracts

In order to prepare methanol leaf extracts, $R$. officinalis leaves were dried in an oven at $40^{\circ} \mathrm{C}$ for $72 \mathrm{~h}$. Subsequently, $3 \mathrm{~g}$ of dried leaf sample was macerated in 100 $\mathrm{mL}$ of methanol for 4 to $6 \mathrm{~h}$ in a Soxhlet device. The extract volume was then reduced to $10 \mathrm{~mL}$ in a Büchi rotoevaporator and centrifuged for $3 \mathrm{~min}$ at $3000 \mathrm{x} \mathrm{g}$. The supernatant was filtered through a Whatman paper (GF/A, $110 \mathrm{~mm}$ )and stored at $4^{\circ} \mathrm{C}$ until further analysis.

Gas Chromatography-Mass Spectrometry (GC-MS)

Methanol extracts were analysed usinga GC-MS system (Agilent7890A/5975C GC-MS System) equipped with a JWMS5capillary column (Agilent Technologies;30mx $25 \mathrm{~mm} \times 0.25 \mu \mathrm{m})$. The chromatographic conditions used is shown in Table 1.

Table.1: Chromatographic conditions used for $G C-M S$ analysis of methanol extracts ofRosmarinus officinalis $L$.

\begin{tabular}{ll}
\multicolumn{2}{c}{ leaves } \\
\hline Parameters & Conditions \\
\hline Helium carrier gas flux & $1 \mathrm{~mL} \mathrm{~min}^{-1}$ \\
Injection volume & $1 \mu \mathrm{L}$ \\
Injector temperature & $270^{\circ} \mathrm{C}$ \\
Source temperature & $290^{\circ} \mathrm{C}$ \\
Interface temperature & $230^{\circ} \mathrm{C}$ \\
Column temperature & $60-290^{\circ} \mathrm{C}\left(5^{\circ} \mathrm{C} / \mathrm{min}\right)$ \\
Injector & automatic \\
Flux range & $0,95 \mathrm{mLmin}^{-1}$ \\
Massspectra & $70 \mathrm{eV}$ \\
Splitratio & $1: 40$ \\
\hline
\end{tabular}

Chromatograms were analyzed usingthe Automated Mass Spectral Deconvolution and Identification System(AMDIS)(MSChem) and the resulting spectra were compared tothe NIST/EPA/NIH Mass Spectral Library 2011 (National Institute of Standards and Technology, Standard Reference Mass Spectra Database, USA).

Thin Layer Chromatography/High Performance ThinLayer Chromatography (TLC/ HPTLC)

Methanol extracts were also analysedusing a CAMAG TLC/HPTLC system equipped with a Linomat V applicator, a TLC scanner 3 and a 12 bit CCD camera for photo documentation, controlled by WinCATS-4 software.A sample volume of $10 \mu \mathrm{L}$ was spotted in $5 \mathrm{~mm}$ bands on a precoated silica gel glass plate $(20 \mathrm{~cm}$ x10 cm)usinga CAMAG microliter syringe. For the development of the plate, the mobile phase solvent system consisted of toluene, 
ethyl acetate and formic acid (70:20:10). To visualize the components, plates were first sprayed with vanillin in ethanol $(1 \%)$ and then with a solution of sulfuric acid in ethanol $(10 \%)$. The plate was heated to $110^{\circ} \mathrm{C}$ for $5 \mathrm{~min}$ and then analyzedunder white light for the evaluation of terpenoids and phenylpropanoids. Alternatively, plates were analyzedusing natural product reagent. In this case, they were first sprayed with $1 \%$ methanolic diphenyl boric acidb-ethylamine ester, followed by $5 \%$ ethanolic polyethylene glycol-4000 and then evaluated under UV light $(365 \mathrm{~nm})$ for the detection of rosmarinic acid.For each of the bands observed, the retention factor ( $\mathrm{Rf}$ ) was calculatedas the ratio between the migration distance of the band and the migration distance of the solvent.

\section{RESULTS AND DISCUSSION}

\section{Trichomes in SMF plants}

Glandular structures are known as primary sites of secondary metabolite biosynthesis, secretion and storage, and generally consist of either simple subcutaneous glands or trichomes.Plants of the Lamiaceaefamily presentboth capitate and peltate glandular trichomes. Both have the same basicmorphology, consisting of a basal region, a stalk anda head. Whereas capitate glandular trichomesare formed bya head with one secretory cell and a stalk containingtwo cells, the peltate type consists of a headwith eight secretory cells, one basal epidermal cell,and a wide unicellular stalk (Boix et al., 2011; Fahn, 1979). In R. officinalis, nonglandular trichomes arepresent on the veins and leaf margins andare diverse in morphology,anatomy and microstructure. Basically, they are classified according to their morphology. They canbe either unicellular ormulticellular, and unbranched or branched(Marin et al., 2006; Werker et al., 1985).
Results of this study show that glandular as well as nonglandular trichomes were observed in plants subjected to both irrigation treatments, although non-glandular trichomes were more numerous (Figure 1). The number of both trichome types on the abaxial leaf surface was higher in SMF plants (Figure 1C-D) as compared to control plants (Figure 1A-B). Leaves of control plants contained approximately six peltate trichomes per $\mathrm{mm}^{2}$, whereas those of SMF plants contained 16 per $\mathrm{mm}^{2}$ on average. The trichomes are primary sites for biosynthesis, secretion and storage of secondary metabolites (Taiz et al., 2015). Greater efficiency could then be expected in the production of bioactive compounds for the treated plants, with respect to the control in the relation structure.

However, irrigation with SMF-treated water did not affect trichome structure, which is characterized by a prominent expandable cuticular layer (Boix et al., 2011).

\section{Metabolites in SMF plants}

The metabolites identifiedin methanol extractsof $R$. officinalis control plantsand SMF plants are listed in Table 2. Results show that irrigation with SMF-treated water strongly increased the levels of terpenoids including the bicyclic monoterpenes camphor, endo-borneol and bornyl acetate and the triterpene $\beta$-amyrin. Furthermore, terpenoids were the major class of bioactive compounds present in SMF plants (Table 2). Monoterpenes are produced in glandular trichomes, found on both leaf sides of $R$. officinalis(Boix et al., 2011).Therefore, the increased monoterpene levels in leaves of SMF plants are possibly related to their higher number of glandular trichomes (Figure 1). 


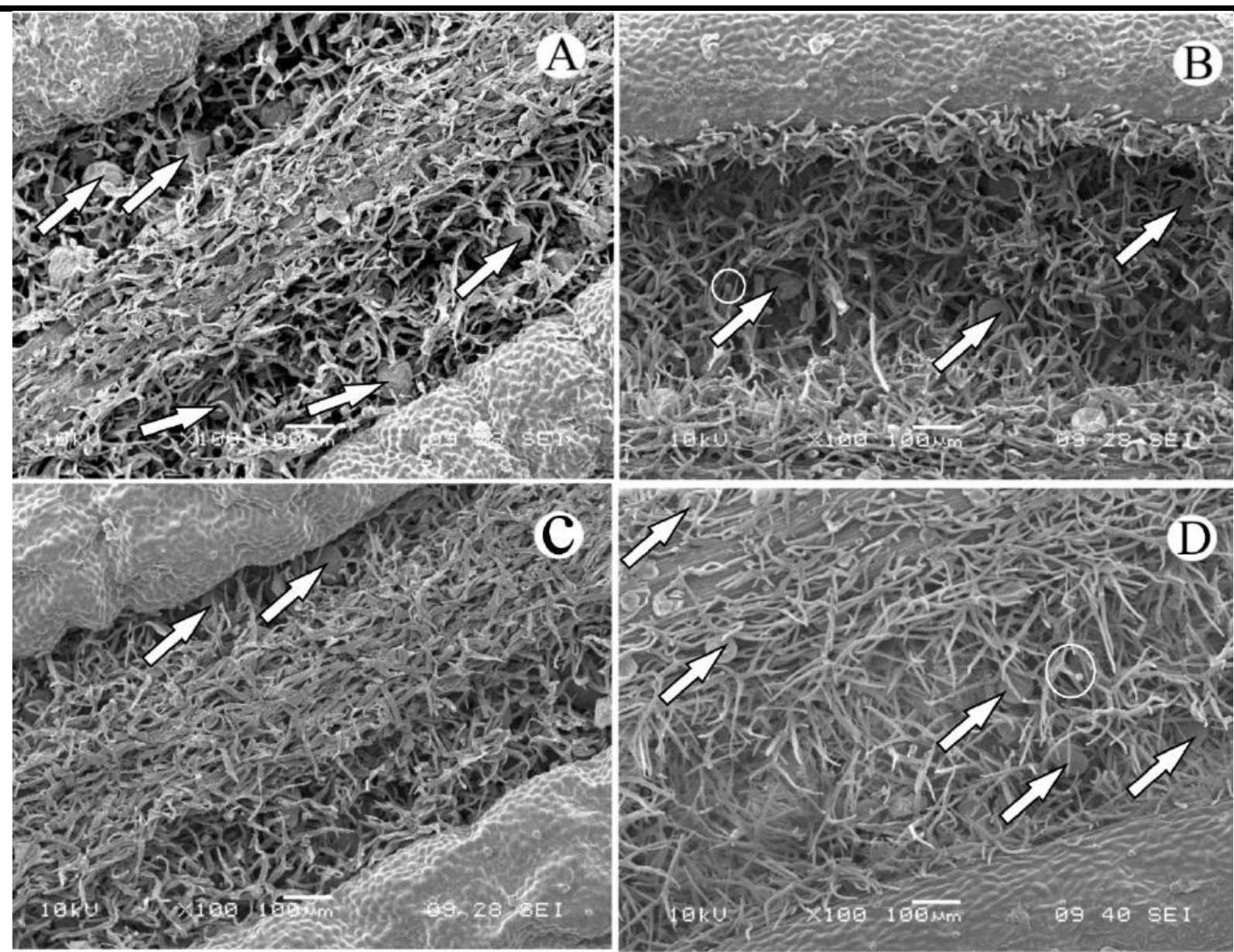

Fig.1: Scanning Electron Microscopic images of the abaxial epidermis of Rosmarinus officinalis L. leaves from control plants $(A-B)$ and SMF plants (C-D). Circle: capitate glandular trichome. Arrow: peltate glandular trichome. Scale bars: $100 \mu \mathrm{m}$.

Table.2: Metabolites detected using GC-MS in methanol leaf extracts of Rosmarinus officinalis L. control and SMF plants.

\begin{tabular}{lccc}
\hline Metabolites & \multicolumn{2}{c}{ Control } \\
\cline { 2 - 4 } & RT & \multicolumn{2}{c}{ Relative area \% } \\
\hline camphor & 6.37 & 16.44 & 23.40 \\
endo-borneol & 6.64 & 1.91 & 7.00 \\
L-alfa-terpineol & 6.80 & 14.00 & 10.3 \\
verbenone & 7.00 & 21.84 & 9.00 \\
camphene & 7.55 & 2.10 & n.d. \\
bornyl acetate & 8.07 & 2.55 & 14.40 \\
2-methoxy-4-vinylphenol & 8.26 & 0.44 & n.d. \\
caryophyllene & 10.92 & 3.41 & 3.40 \\
phytol & 26.40 & 11.21 & 9.00 \\
$\beta$-amyrin & 31.01 & n.d. & 18.10 \\
squalene & 41.32 & 12.05 & n.d. \\
$\alpha$-tocopherol & 51.30 & 13.21 & 5.00 \\
\hline Total & & 99.15 & 99.60 \\
\hline
\end{tabular}


Control: extract obtained from plants irrigated with water not treated with a static magnetic field; SMF: extract obtained from plants irrigated with a static magnetic field; RT: Retention time, n.d.: not detectable.

The related triterpene $\alpha$-amyrin was also isolated from stems and leaves of $R$. officinalis by an extraction procedure using petroleum $\left(60 \sim 90^{\circ} \mathrm{C}\right)$ in a study byZhou et al. (2000). The $\alpha$ - and $\beta$-amyrins are pentacyclic triterpenes of natural origin, isolated from various plant sources such as resin, bark, stems, leaves, roots and rhizomes. Studies have demonstrated the pharmacological effects of these compounds against inflammation,microbial, fungal and viral infections and cancer. Furthermore, amyrins are also involved in the biosynthesis of other biologically active compounds such as avenacin, centelloside, glycyrrhizineand ginsenoside (Vázquez et al., 2012). Therefore, thehigher $\beta$ amyrin levels inleaves of SMF plants as compared to control plantsstrongly suggest a positive effect of irrigation with SMF-treated water on the therapeutic potentialof $R$. officinalis.

Furthermore, camphor concentrations were also increased in methanol leaf extracts of SMF plants as compared to those of control plants (Table 2). This oxygenated monoterpene was detected as the maincompound(23.2\%)in essential oils of $R$. Officinalis leaves, followed by 1,8 cineol (13.4\%), pinene (19.7\%) and verbenone (8.2\%)(Boix Y. F. et al., 2011; Boix Y.F et al., 2014).Like amyrins, camphorhasmany therapeutic properties.Recently, (Rašković et al., 2014) verified the high free radical scavenging activity and hepatoprotective effects of essential oils of aerial plant parts. Interestingly, one of the most abundant compounds present in these oils was camphor.

Furthermore, results of this study showed that bornyl acetate levels were strongly increased in SMF plants as compared to control plants (Table 2). Recent studies showed that bornyl acetate lowered the production of lysophosphatidylcholine (LPS)-induced proinflammatory cytokines suchas TNF- $\square, \mathrm{IL}-1 \mathrm{~b}$, and IL-6. Therefore, irrigation of rosemary with SMF-treated water could possibly increase its anti-inflammatory potential for the treatment of inflammatory processes such as rheumatoid arthritis and osteoarthritis(Yang et al., 2014).

In addition, a decreasedlevel of vitamin $\mathrm{E}$ was found in SMF plants as compared to control plants (Table 2). Vitamin $\mathrm{E}$ is a fat-soluble compound that is mainly localized in membranes, protecting phospholipids against oxidative degeneration by reactive oxygen species (ROS).Itis involved in plantprotection against oxidative damage under differentstress conditions including drought, atmospheric pollutants, photosensitizing fungal toxinsand
chilling(Fryer, 1992).The lower concentration of this vitamin in SMF plantspossibly indicates that irrigation with SMF-treated water diminishesoxidative stress.

Using TLC/HPTLC, the presence of rosmarinic acid was confirmedin methanol extracts of control plants andSMF plants(Figure2), The presence of this compound in $R$. officinalisextracts has already been reported by(Wagner $\mathrm{H}$. et al., 1996). Rosmarinic acid is an ester of caffeic acid and has antioxidant, anti-inflammatory, antibacterial, antiangiogenic, antimutagenic and antiallergenic activities(Nunes et al., 2015).In methanolicextract obtained of control and with SMFplants therosmarinic acid level it was no difference between both conditions. Whereas rosmarinic acid was detected under both irrigation regimes, no differences were observed in the levels of this compound in plants of either group.

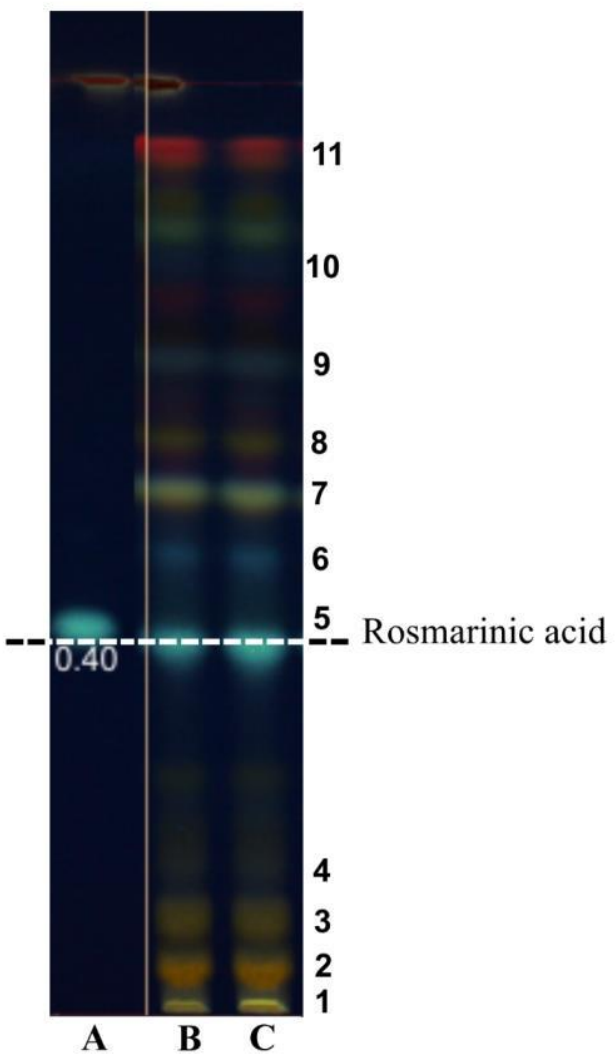

Fig.2: Thin Layer Chromatography/High Resolution Layer Chromatography (TLC/HPTLC) results showing standard rosmarinic acid $(R f=0.40)(A)$, methanolic extracts from leaves of control $(B)$ and SMF Rosmarinus officinalis $L$. plants $(C)$.

Taken together, results of this study indicate that the levels of several secondary metabolites are increased in SMF plants as compared to control plants. This finding possibly explains the fact that irrigation of plants with SMF-treated 
water improves plant growth. The results obtained in this study are in agreement with data available in literature. Indeed, previous studies using wheat plants demonstrated a higher total phenol content in plants irrigated with SMFtreated water as compared to control plants(Amira et al., 2010).Furthermore, it wasdemonstrated that irrigation with SMF-treated water leads to an increase in plant productivity and changes in water and mineral absorption(Hozayn et al., 2013; Mohamed et al., 2013).The amount ofwater assimilated by the plant also affectsrespiration and photosynthesis andthe concentrations of photosynthetic pigments, phenols and indoles.Similarly, research has shown that methanolextracts ofSolanum lycopersicum irrigated with SMF-treated water (150-300mT) had a higher phenolic content as well as a higher antioxidant activity as compared to those of control plants(Dubois et al., 2013). Interestingly, irrigation with SMF-treated water was also shown to increase the fresh and dry weight of tomato plants, implying a positive effect on plant growth (Ahmed A.M., 2013). In addition, Qados (2011)reported that irrigation with SMF-treated water significantly improved the growth and yield, as well as protein content and photosynthetic pigment levels of Vicia faba L. plants.

We hypothesize that the increased levels of secondary metabolites in SMF plants could be related to an effect of SMF-treated water on cell membrane characteristics, resulting in an altered cell metabolism. Indeed, (Formicheva et al. (1992))reported that SMF-treated water significantly induced cell metabolism and mitosis in meristematic cells of pea, lentil and flax. Furthermore, gene transcription playing an important role in regulating cellular processes also seems to be affected by irrigation with SMF-treated water in Pisum sativum and Cicer arietinum(Grewal and Maheshwari, 2011). The effects of irrigation with magnetically treated water on plant secondary metabolite levels could also be a consequence of an influence on hormone levels, as increases in gibberellin $\left(\mathrm{GA}_{3}\right)$ and kinetin levels were observed in broad bean plants irrigated with SMF-treated water (Mohamed et al., 2013).

The effects of irrigation with SMF-treated water on these processes could be caused by changes occurring in the physical and chemical properties of water after application of a static magnetic field(Grewal et al., 2011b).

\section{CONCLUSION}

Overall, results of this study indicate that irrigation with SMF-treated water could be used as a strategy to increase secondary metabolite levels in Rosmarinus officinalis, thereby promoting its therapeutic potential.

\section{ACKNOWLEDGMENT}

We thank Dr. Fidel Gilart Gonzalez and MSc. Douglas De As Yero of CNEA for magnetic field characterization and Dr. J. D. Sepúlveda of the Universidad Autónoma Metropolitana (UAM) - Iztapalapa (Mexico) for scanning electronic microscopy. We also thank theVLIR/UO (Belgium/Cuba) international program and the Centre for Environmental Sciences in Diepenbeek for financial support.We are also grateful to the International Scholarship Program sponsored by the Mexican Secretary of State of Exterior Relations and University of Oriente (Mexico/Cuba) and specifically CINVESTAV/Irapuato for financial support.

\section{CONFLICT OF INTEREST STATEMENT}

The authors declare that they have no conflict of interest.

\section{REFERENCES}

[1] Ahmed A.M. (2013): Effects of Magnetized Low Quality Water on Some Soil Properties and Plant Growth. Internatinal Journal of Research in Chemistryand Environment, 3: 140-147.

[2] Al-Sereiti MR, Abu-Amer KM, Sen P. (1999): Pharmacology of rosemary (Rosmarinus officinalis Linn.) and its therapeutic potentials. Indian Journal of Experimental Biology, 37.

[3] Amira M S, Qados A, Hozayn M. (2010): Response of growth, yield, yield components, and some chemical constituents of flax for irrigation with magnetized and tap wáter. World Applied Science Journal, 8: 630-634.

[4] Boix Y. F., Victório C. P., A. Defaveri A.C.A., Arruda R.C.O., Sato A., Lage C. L. S. (2011): Glandular trichomes of Rosmarinus officinalis L.: Anatomical and phytochemical analyses of leaf volatiles. Plant Biosystems: 1-9.

[5] Boix Y.F, Victório C.P., Arruda R.C.O, Lage C.L.S. (2014): Volatile oil constituents of Rosmarinus officinalis L. obtained in open-air market from Rio de Janeiro. International Journal of Biology Pharmacy and Allied Sciences (IJBPAS), 3: 541-548.

[6] Dubois AF, Leite G, Rocha J. (2013): Irrigation of Solanum lycopersicum L. with magnetically treated water increases antioxidant properties of its tomato fruits. Electromagnetic Biology and Medicine, 32: 355-362.

[7] Fahn A. (1979): Secretory tissues in plants, London: Academic Press Inc.

[8] Fernández L.F., Palomino O.M., Frutos G. (2014): Effectiveness of Rosmarinus officinalis essential oil as antihypotensive agentin primary hypotensive patients 
and its influence on health-related quality of life. Journal of Ethnopharmacology 151: 509-516.

[9] Formicheva V.M., Zaslavskii V.A., Govorun R.D., Danilov V.T. (1992): Dynamics of RNA and protein synthesis in the cel1s of the root meristems of the pea, lentil and flax Biophysics 37: 649-656.

[10] Fryer MJ. (1992): The antioxidant effects of thylakoid Vitamin E ( $\alpha$-tocopherol). Plant, Cell \& Environment, 15: 381-392.

[11] Gesterberger P., Leins P. (1978): Rasterelektronenmikroskopische Untersuchungen an Blütenknospen von Physalis Philadelphia (Solanaceae). . Ber Dt Bot Ges, 91: 381-387.

[12] Gilart F., Deas D., Ferrer D., Lopez L., Ribeaux G., Castillo J. (2013): Hight flow capacity devices for anti-scale magnetic tretament water Chemical Engineering and Processing: Process Intensification, 70: 211-216.

[13] Grewal H.S., Maheshwari B.L. (2011a): Magnetic treatment of irrigation water and snow pea and Chickpea seeds enhances early growth and nutrient contents of seedlings. Bioelectromagnetics, 32: 58.

[14] Grewal H.S., Maheshwari B.L. (2011b): Magnetic treatment of irrigation water and snow pea and chickpea seeds enhances early growth and nutrient contents of seedlings. Bioelectromagnetics, 32: 58-65.

[15] Hozayn M, El Monem A, Abdelraouf R, Abdalla M. (2013): Do Magnetic Water Affect Water Use Efficiency, Quality and Yield of Sugar Beet (Beta vulgaris L.) Plant under Arid Regions Conditions? Journal of Agronomy 12: 1-10.

[16] Johansen DA. (1940): Plant Microtechnique. McGrawHill, New York, 523.

[17] Marin M., Koko V., Duletic-Lausevic S, Marin P.D, Rancic D, Z. D-S, Galisteo M. (2006): Glandular trichomes on the leaves of Rosmarinus officinalis: morphology, stereology and histochemistry. South African Journal of Botany, 72: 378-382.

[18] Mohamed A. I., Ebead B. M. (2013): Effect of irrigation with magnetically treated water on faba bean growth and composition. International Journal of Agricultural Policy and Research, 1: 024-040.
[19] Mohamed AI, Ebead BM. (2013): Effect of magnetic treated irrigation water on salt removal from a sandy soil and on the availability of certain nutrients. International Journal of Engineering, 2: 2305-8269.

[20] Nunes S, Madureira R, Campos D, Sarmento B, Gomes AM, Pintado M, Reis F. (2015): Therapeutic and Nutraceutical Potential of Rosmarinic Acid Cytoprotective Properties and Pharmacokinetic Profile Critical Reviews in Food Science and Nutrition.

[21] Qados AMA. (2011): Effect of salt stress on plant growth and metabolism of bean plant Vicia faba (L.). Journal of the Saudi Society of Agricultural Sciences, 10: 7-15.

[22] Rašković A, Milanović I, Pavlović N, Ćebović T, Vukmirović S, Mikov M. (2014): Antioxidant activity of rosemary (Rosmarinus officinalis L.) essential oil and its hepatoprotective potential. BMC Complementary and Alternative Medicine, 14: 1-9.

[23] Suong NTN, Desmond BW, Richard JH. (2011): Rosemary and cancer prevention: preclinical perspectives. Critical Reviews in Food Science and Nutrition, 51: 946-954.

[24] Taiz L, Zeiger E, Møller IM, Murphy A. (2015): Plant Physiology and Development. Sixth. Sinauer Associates, Incorporated, California, USA.

[25] Vázquez LH, Palazon J, Navarro-Ocaña A. (2012): The Pentacyclic Triterpenes $\alpha, \beta$-amyrins: a review of sources and biological activities, Phytochemicals - A Global Perspective of Their Role in Nutrition and Health. Dr Venketeshwer Rao (Ed.).

[26] Wagner H., Baldt S., Zgainski EM. (1996): Plant drug analaysis. Springer Science \& Business Media, Berlin.

[27] Werker E, Ravid U, Putievsky E. (1985): Structure of glandular hairs and identification of the main components of their secreted material in some species of the Labiatae. Israel Journal of Botany, 34: 31-45.

[28] Yang H, Zhao R, Chen H, Jia P, Bao L, Tang H. (2014): Bornyl acetate has an anti-inflammatory effect in human chondrocytes via induction of IL-11. IUBMB life, 66: 854-859. 